\title{
MICHAEL LÖWY E A SOCIOLOGIA DO TRABALHO: a descoberta da consciência de classe do operariado
}

\author{
Ricardo Festi*
}

\begin{abstract}
O artigo busca analisar e problematizar a rápida passagem do jovem Michael Löwy pela sociologia do trabalho, quando realizou, em 1959, uma pesquisa sobre as atitudes e a consciência operária entre dirigentes sindicais metalúrgicos. Para isso, contextualiza esse estudo no curso do processo de institucionalização da sociologia brasileira, em particular o desenvolvimento das pesquisas acerca da indústria e do trabalho realizadas na Universidade de São Paulo, nas décadas de 1950 e 1960. Como conclusão, pode-se afirmar que Löwy apresentou, já àquela época, num manuscrito até então desconhecido, uma possível alternativa ao estilo de sociologia vigente na USP. As reflexões e conclusões deste artigo estão ancoradas em consultas realizadas em arquivos e numa entrevista com o próprio autor.
\end{abstract}

Palavras-chave: Michael Löwy. Sociologia do trabalho. Consciência operária. Pensamento social. História intelectual.

O objetivo deste artigo é refletir sobre um momento particular e pouco conhecido da trajetória do jovem Michael Löwy: sua pequena passagem pela sociologia do trabalho. Esse fato se deu quando Löwy ainda era estudante do curso de graduação em ciências sociais pela Universidade de São Paulo (USP) e realizou uma pesquisa sob a supervisão de Aziz Simão, para a disciplina "Prática de Pesquisa", oferecida pela Cadeira II de Sociologia, sobre as atitudes e a consciência operária. A metodologia utilizada para tal pesquisa foi a aplicação de um questionário aos delegados do II Congresso Nacional de Trabalhadores Metalúrgicos, realizado em abril de 1959, em Itanhaém (SP). As motivações de fundo do autor para a escolha desse tema transbordavam o mundo acadêmico, pois ele buscava responder, ainda que parcialmente, as inquietações teóricas e políticas que vinha nutrindo desde que assumiu uma perspectiva crítica ao mundo capitalista.

* Universidade Estadual de Campinas - Unicamp (campus Limeira).

Rua Paschoal Marmo, 1888. Cep: 13484-332. Jardim Nova Itália - Limeira - São Paulo - Brasil. ricardofesti@gmail.com
A realização de sua pesquisa foi um empreendimento coletivo. A fase de elaboração e aplicação dos questionários contou com as opiniões de lideranças operárias e com a orientação de Albertino Rodrigues, então diretor do recém-criado e respeitado Departamento Intersindical de Estatística e Estudos Socioeconômicos (DIEESE). Junto aos quadros desse instituto, Sarah Chucid, ${ }^{1}$ recém-ingressante na USP, trabalhava como assistente de pesquisa e tornou-se parceira de Löwy na realização dessa investigação junto aos delegados sindicais. Havia uma identificação política e social entre os dois estudantes, o que os conduzia às mesmas inquietações. Chucid era filha de imigrantes judeus e escolheu o curso de ciências sociais, pois desejava transformar a sociedade. Ela mesma, anos mais tarde, escreveu sobre isso: " $(\mathrm{Eu})$ tinha em mente uma atitude idealista de questionamento da sociedade, ao mesmo tem-

${ }^{1}$ Antes de cursar ciências sociais (1959-1963), Sarah Chucid colaborou, em 1957, com as pesquisas do Centro Regional de Pesquisas Educacionais da USP, dirigido por Fernando de Azevedo, e foi assistente de pesquisa no DIEESE junto ao primeiro levantamento de índice do custo de vida da cidade de São Paulo, em 1958. Defendeu uma tese de doutorado em 1973, na ECA-USP, com o título "Mudança nas atitudes e opiniões do trabalhador têxtil brasileiro ante os meios de comunicação de massa”. 
po em que agasalhava no espírito a sensação e o desejo de que, de alguma forma, eu pudesse me engajar na perspectiva de transformá-la" (Viá, 1986). ${ }^{2}$

A pesquisa empreendida por Löwy e Chucid, em 1959, tinha como objetivo principal evidenciar, por meio de um survey, as opiniões e as atitudes de operários sindicalizados em uma gama diversa de problemas sindicais e político-sociais. Inicialmente, eles planejavam a aplicação dos questionários para uma grande quantidade de operários. No entanto, aproveitando-se do fato de que vários congressos sindicais estavam para ocorrer em São Paulo e no Rio de Janeiro, decidiram aplicá-lo, primeiramente, entre os delegados de um desses encontros. Portanto, a sondagem realizada no congresso metalúrgico foi, posteriormente, apresentada como uma primeira aproximação de um "setor da realidade social quase inexplorado sociologicamente, e que não pretende senão levantar hipóteses que servirão aos estudos posteriores do problema" (Manuscrito, p. 1).

$\mathrm{O}$ resultado da pesquisa realizada em 1959 deu origem a duas publicações e a um manuscrito. Uma das publicações, assinada pelos dois estudantes, saiu na Revista Brasileira de Estudos Políticos, $\mathrm{n}^{\circ} 13$, de janeiro de 1962, sob o título Opiniões e atitudes de líderes sindicais metalúrgicos. A outra publicação saiu em francês, no $\mathrm{n}^{\circ} 49$ da prestigiosa revista Cahier Internationaux de Sociologie, em julho de 1970. Essa versão foi traduzida para o português e publicada no dossiê "A obra polissêmica de Michael Löwy”, no qual se insere o presente artigo, com o título Estrutura e consciência de classe operária no Brasil. ${ }^{3}$

Neste artigo, serão analisados esses três textos, buscando evidenciar suas semelhanças

\footnotetext{
${ }^{2}$ Sobre as motivações políticas do jovem Löwy, ver a entrevista publicada no Dossiê deste número: "A obra polissêmica de Michael Löwy”.

${ }^{3}$ Para facilitar, citaremos os três textos mencionados da seguinte maneira: o artigo escrito em coautoria com Sara Chucid será citado simplesmente como Artigo de 62; já o artigo em francês, cuja tradução é publicada no dossiê citado acima, será denominado Artigo de 70 ; e, por fim, o manuscrito será identificado como Manuscrito.
}

e, principalmente, suas diferenças metodológicas, analíticas e conclusivas, levando em consideração os contextos de produção e publicação, bem como as distâncias de estilo e de perspectiva. Hoje, o valor desses textos é muito mais histórico do que sociológico, pois são testemunhas de um momento-chave no desenvolvimento e na institucionalização da sociologia do trabalho no Brasil e, em particular, na USP. Por isso, a confrontação entre eles clarifica as tensões que existiam no interior dessa "escola sociológica”. Nesse sentido, sustentamos que o Artigo de 62 é um produto exemplar da sociologia uspiana dos anos 1950-1960, ${ }^{4}$ enquanto o Manuscrito e o Artigo de 70 apresentam uma perspectiva teórico-política alternativa, que encontrou espaço, na academia brasileira, apenas décadas depois.

Além de um estudo minucioso e comparativo entre os textos, as conclusões deste artigo estão amparadas em pesquisas realizadas em documentos depositados em arquivos do Brasil e da França e em diversas fontes bibliográficas, além de uma entrevista realizada com Michael Löwy e publicada, também, no citado dossiê.

\section{A MEMÓRIA REVISITADA}

No prefácio ao livro de Ruy Braga (2012), A política do precariado, Löwy recorda-se dessa pesquisa realizada no final dos anos 1950 e escreve:

[...] confesso que meu interesse se dirigiu sobretudo para a primeira [parte do livro], em particular no que concerne os anos 1950, pela simples razão de que acompanhei o processo de perto, tanto como aluno e amigo de Azis Simão, um dos pioneiros dos estudos sobre a classe operária no Brasil, quanto como colaborador no Dieese de Albertino Rodrigues, e, last but not least, como delegado da União Estadual dos Estudantes junto ao Pacto Intersindical. E nesse contexto que tive a ocasião de levar a cabo, com o acordo do Dieese, a uma enquete sobre a consciência de classe

\footnotetext{
${ }^{4}$ Veja que, na primeira nota deste texto, os autores mencionam as colaborações críticas que receberam de Florestan
} Fernandes, Fernando Henrique Cardoso e Octávio Ianni. 
de militantes sindicais, a partir de um questionário distribuído aos delegados do Congresso dos Trabalhadores Metalúrgicos de 1960. Uma primeira versão deste trabalho (em colaboração com Sarah Chucid) foi publicada com o título ‘Opinióes e atitudes de dirigentes sindicais metalúrgicos'. Uma segunda versão, mais ambiciosa do ponto de vista teórico, apareceu como 'Structure de la conscience de classe Ouvrière au Brésil'. As conclusões desta pesquisa são bastante diferentes - na medida em que apontam para uma consciência de classe politizada - da enquete sobre a consciência sindical levada adiante mais ou menos na mesma época por Leôncio Martins Rodrigues - e examinada, com pertinência, por Ruy Braga (Braga, 2012, p. 12-13).

A passagem pode ser esclarecedora em alguns aspectos, principalmente para aqueles que não tiveram contato com os textos mais antigos de Löwy. No entanto, para um estudo mais detalhado, essa mesma passagem pode nos conduzir a conclusões equivocadas acerca das diferenças entre a primeira e a segunda publicação, originadas da mesma pesquisa realizada em abril de 1959 (e não 1960). Uma reflexão apressada nos levaria a considerar, tomando-se apenas as datas das publicações (1962 e 1970) e o que foi enunciado acima, que as duas pertencem a momentos distintos do percurso intelectual do autor. A afirmação de Löwy de que a segunda versão teria sido "mais ambiciosa do ponto de vista teórico" pode ser interpretada a partir de uma perspectiva cronológica, ou seja, levando em conta um amadurecimento intelectual do autor, já que, no intervalo entre 1962 e 1970, ele defendeu, na França, sua tese de doutorado sobre o jovem Marx, sob orientação de Lucien Goldmann, e foi professor das universidades de Israel e da Inglaterra. ${ }^{5}$

No entanto, a consulta aos arquivos de Azis Simão ${ }^{6}$ responde a algumas das especula-

\footnotetext{
${ }^{5}$ Não nos esqueçamos de que, também nesse intervalo de tempo, vários fatos políticos de grande envergadura marcaram a vida pessoal, profissional e intelectual de Löwy: Golpe de 64 no Brasil e as revoltas operário-estudantis em 1968, na França.

${ }^{6}$ Referimo-nos aos documentos depositados no Centro de Apoio à Pesquisa em História Sérgio Buarque de Holanda $(\mathrm{CAPH})$, do Departamento de História da FFLCH-USP. Outra parte dos documentos de Simão, principalmente os livros e as fitas cassetes, encontra-se no Arquivo Edgar Leuenroth (AEL) da Unicamp.
}

ções possíveis acerca da produção desses textos, pois neles encontramos dois documentos datilografados pelo então jovem e estudante Löwy sobre a pesquisa de 1959. Um deles é, literalmente, o texto publicado na Revista Brasileira de Estudos Políticos em 1962, em coautoria com Sarah Chucid, enquanto que o outro é praticamente o mesmo artigo que saiu, anos mais tarde, no Cahier Internationaux de Sociologie (Cf. Simão). Os dois documentos não estão datados, mas um olhar atento às referências bibliográficas do segundo manuscrito nos leva a concluir que ele foi finalizado e entregue a Simão entre finais de 1959 e início de 1960, ou seja, embora um tenha sido publicado anos depois, ambos foram escritos na mesma época. Uma passagem do segundo manuscrito também deixa claro que ele foi escrito depois do primeiro (o que deu origem ao Artigo de 62): "parte do mesmo, constituída pelos delegados de S. Paulo, Rio e Guanabara, já foi objeto de estudo, sob um ângulo mais geral, em trabalho a ser publicado (M. Löwy e S. Chucid, Opiniões e atitudes de líderes sindicais metalúrgicos, S. Paulo, 1961)" (Manuscrito, p. 1).

Podemos, então, especular que Löwy, não satisfeito com o manuscrito escrito em coautoria com Chucid (e que deu origem à publicação de 62), demasiadamente formal e enquadrado no estilo uspiano de sociologia daquele momento, resolveu escrever e apresentar para o seu amigo Azis Simão uma segunda versão com suas próprias interpretações e aportes, tendo agora a liberdade de desenvolvê-la sob o marco teórico do marxismo. A versão publicada em francês, em 1970, recebeu poucas correções e acréscimos em relação ao Manuscrito, mantendo todas as questões teóricas fundamentais já presentes para a compreensão do seu objeto.

O rascunho do artigo escrito em 1959, em coautoria com Chucid e publicado em 1962, contou com observações críticas de Florestan Fernandes, Fernando Henrique Cardoso e Octávio Ianni. Devido à metodologia utilizada na análise das respostas aos questionários aplicados e à forma como o texto foi exposto, 
podemos afirmar que ele estava mais próximo dos padrões da sociologia do trabalho que vinha sendo gestada na USP, ${ }^{7}$ Afirmar isso não diminui a importância desse trabalho, que apresentou um novo campo de pesquisa para a época. Já o artigo que foi base da publicação em francês, assinado apenas por Löwy, pode ser lido como uma alternativa em potencial, não desenvolvida posteriormente, ao tipo de pesquisa e de análise que se consolidou na década de 1960 entre os sociólogos da USP.

Esse fato nos conduz a levantar duas questões de ordem metodológica. A primeira é que, do ponto de vista de uma sociologia que visa a compreender a obra de um autor ou de um determinado grupo de autores, é fundamental um olhar crítico às narrativas e memórias elaboradas por eles e por seus colaboradores. Como nos ressalta Miceli (1989), é comum encontrar, nessas representações e hierarquizações que buscam reconstruir o passado, certas distorções ou valorizações de determinados fatos em detrimento de outros, o que serve para fortificar certas posições ou interesses no presente. A historiografia também nos alerta para o fato de que a memória é permeada por uma narrativa enevoada - muitas vezes, como consequência de simples esquecimento -, o que reforça o argumento de que os silêncios e os fragmentos nas narrativas são também objetos importantes de reflexões. Por fim, essas duas observações nos levam à segunda questão metodológica, isto é, à importância da pesquisa em arquivos para os estudos em sociologia das ideias.

Como afirmamos, buscaremos demonstrar as proximidades e as diferenças entre esses dois artigos. Para aqueles que buscam uma explicação sociológica sobre as atitudes de líderes sindicais do período em questão, ou simplesmente um olhar histórico sobre a sociologia brasileira, os dois artigos devem ser lidos como complementares, tendo em vista suas diferenças analíticas, pois apresentam resultados e análises reflexivas a partir de dados coletados na mesma pesquisa. Entretanto, se o objetivo é desvendar o porquê dessas duas

${ }^{7}$ É nesse período, entre 1958 e 1960, que dois representantes da sociologia do trabalho francesa vêm a USP aportar no desenvolvimento dessa especialidade e na criação do futuro CESIT, conforme demonstraremos logo a seguir. publicações, devem-se ressaltar as substanciais diferenças entre os métodos empregados para analisar os dados, o que levou a diferentes abordagens, ainda que se tenha chegado a conclusões gerais similares.

\section{A CRIAÇÃO DE UMA NOVA DISCI- PLINA: sociologia do trabalho}

Antes de ingressar na análise propriamente dos textos, ressaltando suas aproximações e diferenças, abordaremos o contexto em que eles foram produzidos, situando-os no curso da institucionalização da sociologia uspiana e, em particular, no surgir da sociologia do trabalho como uma nova disciplina que, como demonstraremos, foi um projeto político-acadêmico de muitos autores e que teve, na USP, uma instituição privilegiada para seu desenvolvimento durante um período de profundas transformações no Brasil, com a urbanização e a industrialização.

O Artigo de 62 (Chucid e Löwy) começa com a citação de uma passagem de Florestan Fernandes na qual ele defende que "os sociólogos precisam adotar uma nova orientação: a) abandonar as esferas puramente teóricas de discussão de problemas; b) orientando seus esforços no sentido de alcançar o mais depressa possível os objetivos que justificam a sociologia como ciência” (Fernandes, 1947, p. 345). Essa posição foi mais bem desenvolvida por Fernandes ao longo da década de 1950, principalmente depois que assumiu o lugar de Roger Bastide, na Cadeira I de Sociologia, e passou a ministrar a disciplina "Sociologia Aplicada", quando aprofundou uma concepção de ciência social que buscava não se restringir puramente à esfera teórica, como preconizava a tradição francesa difundida até então na USP, e sim voltar-se aos problemas concretos da sociedade. Para esse tipo de sociologia, aplicada numa era de "revolução social", como caracterizava o autor, era fundamental que as pesquisas tivessem um forte embasamento empírico (Cf. Fernandes, 1960, 1962).

Esse movimento em direção a uma "sociologia científica”, que criticou duramente as 
tendências filosofantes e ensaísticas, foi comum em todos os principais centros em que a sociologia floresceu como uma nova ciência do mundo pós-Segunda Guerra. Foi assim na França, com Georges Gurvitch e Georges Friedmann; na Argentina, com Gino Germani e Torcuato di Tella; e, no Brasil, com a "sociologia paulista”. Em geral, esses centros receberam forte influência das ciências sociais dos EUA local onde, de fato, a sociologia estava mais desenvolvida institucionalmente -, em particular da tradição de Chicago e de seus estudos de comunidade. ${ }^{8}$ Sobre isso, é importante destacar o papel decisivo que teve Donald Pierson, como professor da Escola Livre de Sociologia e Política de São Paulo (Cf. Brochier, 2016).

Portanto, os primeiros estudos sobre a classe operária e o mundo industrial realizados na USP foram fortemente influenciados pela sociologia norte-americana, notavelmente a sociologia industrial criada nos anos $1920 \mathrm{com}$ os estudos de Elton Mayo e seus discípulos da Escola das Relações Humanas. A monografia que Mario Wagner Vieira da Cunha apresentou ao concurso de 1951, para a cátedra de Ciência da Administração e Estrutura das Organizações Econômicas, da Faculdade de Ciências Econômicas e Administrativas da USP, pode ser considerada o primeiro estudo de sociologia industrial inspirado nessa tradição (Cf. Cunha, 1951). As ideias ali apresentadas cumpriram um importante papel na formação das novas gerações, como foi o caso de Fernando Henrique Cardoso, quando assistente na FCEA-USP entre os anos 1952 e1953.

Estamos denominando de sociologia do trabalho todos os estudos que foram realizados ao longo dos anos 1950 e 1960, no interior da USP, sobre a classe trabalhadora e o mundo do trabalho. Apesar de estar em curso um projeto de institucionalização desse domínio como uma nova disciplina, o mundo do trabalho era,

${ }^{8}$ Como afirmou Fernando Henrique Cardoso, em entrevista concedida ao autor $(06.12 .2017)$, Florestan pretendia, em meados dos anos 1950, com os estudos sobre a questão racial, fazer em São Paulo o que se havia feito em Chicago. Para um estudo mais detalhado sobre a tradição de Chicago, ver Chapoulie (2001). de fato, um tema transversal, abordado por diversos autores, de diferentes grupos e cátedras $^{9}$ (Cf. Guimarães; Leite, 1994). Por isso, em última instância, assumimos a concepção francesa de sociologia do trabalho da década de 1960, ou seja, aquela que compreende o trabalho como categoria fundamental e fundante da sociedade contemporânea.

Devemos acrescentar, nessa curta contextualização, os estudos empreendidos por Azis Simão, na primeira metade dos anos 1950, em particular aquele sobre o voto operário em São Paulo (Simão, 1955). A apresentação de seus resultados no I Congresso Brasileiro de Sociologia, em 1954, realizado na cidade de São Paulo, causou grande impacto na recém-formada comunidade de sociologia do Brasil. Muitos estudos sobre a institucionalização da sociologia citam esse trabalho de Simão, mas poucos o analisam. Sem espaço para fazer isso no presente trabalho, vale destacar que o professor aplicou, pela primeira vez, o método de survey e apresentou, com originalidade, uma reflexão sobre as atitudes dos operários perante o voto, problematizando o fenômeno do "trabalhismo" - ainda não estava em voga o termo populismo.

Por fim, na segunda metade da década de 1950, Juarez Brandão Lopes realizou os seus estudos sobre as atitudes operárias em algumas fábricas. Desses estudos, o autor começa a formular certas teses que viraram a marca da sociologia do trabalho uspiana. O operário, recém-migrado do meio rural, tinha dificuldades em se adaptar ao novo meio urbano e industrial, carregando consigo um anseio de ascensão social e de fuga da condição operária. Essa atitude marcaria um traço conservador do operariado brasileiro e a sua incapacidade de construir um projeto de negação da ordem capitalista (Cf. Antunes, 1982, 1988).

${ }^{9}$ Lembremos que, naquele momento, a USP funcionava
a partir de cátedras, o que dificultava a ascensão de no-
vos professores e pesquisadores. Essa rigidez fez com que
houvesse uma dispersão dos sociólogos em diferentes ca-
deiras. Mario Wagner Vieira da Cunha foi para o Instituto
de Administração. Juarez Brandão, para a Faculdade de
Arquitetura e Urbanismo. Azis Simão estava na Cadeira II,
dirigida por Fernando de Azevedo.


A sociologia do trabalho brasileira ainda carece de uma obra capaz de reconstruir e analisar sua história, com o rigor científico e analítico, diferenciando as suas várias etapas. O que existe, atualmente, é apenas um conjunto de trabalhos, teses, artigos, ensaios ou relatos de protagonistas e discípulos que visa a explorar determinados aspectos dessa empreitada, acabando por ressaltar os projetos científicos de um único sociólogo ou de um grupo de sociólogos. ${ }^{10}$ Nesses estudos, o Centro de Sociologia Industrial e do Trabalho (CESIT), criado em 1961, recebeu especial destaque e é apresentado como percursor da sociologia do trabalho no Brasil. ${ }^{11}$

Segundo as palavras de um dos protagonistas na criação do CESIT, Fernando Henrique Cardoso (2012), “o Fernando de Azevedo trouxe para o Brasil um outro francês, que era o patron do (Alain) Touraine, que era professor do Conservatoire dês Arts et Métiers, na França, Friedmann, Georges Friedmann. Este homem estava desenvolvendo a sociologia do trabalho, que era novidade". Leôncio Martins Rodrigues (2010), outro partícipe desse projeto, também reforça a narrativa de que o CESIT foi percursor da sociologia do trabalho no Brasil, após a chegada desse grupo de franceses. O problema dessa versão é que ela desconsidera todas as empreitadas individuais e isoladas que foram realizadas ao longo de toda a década de 1950, conforme apontamos anteriormente. Foi sob a predominância desse discurso de sobrevalorização do CESIT que a pesquisa de Michael Löwy e Sarah Chucid, inovadora em sua época, acabou não recebendo a devida valorização e seu lugar na história da sociologia do trabalho brasileira.

Quando Friedmann visitou pela primeira vez a USP, em 1958, ficou impressionado com o grupo de jovens sociólogos que participou de seu Seminário sobre sociologia industrial. Ele se animara ao ver que, durante quase uma década, sociólogos brasileiros se debruçaram sobre o problema da industrialização e da

${ }^{10}$ Alguns exemplos de artigos e teses nesse sentido: Romão (2006), Cândido (2002), Guimarães e Leite (1994) e Lopes, Pessanha e Ramalho (2012).

${ }^{11}$ Para uma maior problematização da constituição da sociologia do trabalho na USP, ver Festi (2017). modernização da sociedade ${ }^{12}$ e, em particular, estavam dispostos a construir uma sociologia capaz de intervir na realidade em plena transformação. Foi nessa ocasião que o francês sugeriu que fosse criado o CESIT, um laboratório que poderia atuar em cooperação com os experimentos similares na França.

A pesquisa em arquivos da França e do Brasil nos permitiu problematizar esse "mito fundador" e descobrir que a sociologia do trabalho e, em particular, a relação estabelecida entre esse grupo de brasileiros e os franceses em torno da questão do trabalho teve início muito tempo antes e refletiu tanto um empreendimento nacional, que contou com uma colaboração entre Fernando de Azevedo, da Cadeira I de Sociologia da USP, e Anísio Teixeira, presidente da CAPES,,$^{13}$ como um longo processo de relações acadêmico-pessoais que culminou, no final dos anos 1950, na consolidação de uma comunidade científica internacional de ciências sociais.

Friedmann e os sociólogos da USP, por exemplo, vinham alimentando relações político-acadêmicas com a Associação Internacional de Sociologia (ISA) desde sua fundação O francês foi presidente da ISA e da FLACSO na segunda metade dos anos 1950. Os brasileiros Fernando de Azevedo e Luiz Aguiar da Costa Pinto fizeram parte da diretoria da ISA, sendo que o primeiro foi seu vice-presidente entre 1950 e 1952. A relação entre franceses e brasileiros em torno da questão do trabalho aprofundou-se com a criação da Faculdade Latino Americana de Ciências Sociais (FLACSO), em Santiago do Chile, e do Centro Latino Americano de Pesquisas em Ciências Sociais (CLAPCS), no Rio de Janeiro, empreendimentos que contaram com volumosos incentivos financeiros e políticos de organizações internacionais, como a UNESCO. Um de seus temas de reflexão foi a

\footnotetext{
${ }^{12}$ Lembremos que Fernando Henrique Cardoso vinha realizando pesquisas sobre a classe trabalhadora e a industrialização. Em 1952, ministrou curso de História Econômica da Europa na FCEA-USP, por indicação de Mario Wagner Vieira da Cunha. Sua especialização, realizada entre 1952 e1953, foi sobre a industrialização de S. Paulo. Mesmo durante a pesquisa sobre a questão racial, continuou preocupado com essa temática. Cf. relato de FHC em entrevista concedida ao autor em 06.12.2017.

${ }^{13}$ Recordemos que a CAPES foi criada em 1951 e tinha como uma de suas funções aprimorar as relações entre as universidades brasileiras e as estrangeiras.
} 
questão da industrialização das sociedades subdesenvolvidas, em particular a questão da resistência à modernização. ${ }^{14}$ Alguns anos antes, em uma conferência sobre o ensino de ciências sociais na região, realizada no Brasil, votou-se que "as universidades da América do Sul deveriam fomentar ativamente as disciplinas designadas com o nome genérico de Relações Industriais ou Relações de Trabalho". ${ }^{15}$

A relação de Friedmann com os sociólogos da USP teve início, portanto, nos fóruns internacionais, mas foi pela mediação de Fernando de Azevedo e Anísio Teixeira que se articulou sua vinda ao Brasil. Conforme nos revelam as correspondências, o objetivo era de aportar no desenvolvimento da sociologia industrial. O primeiro convite ocorreu em 1954. No entanto, Friedmann, apesar de demonstrar grande interesse pela visita, teve de continuamente adiá-la por excesso de trabalho. ${ }^{16}$ Portanto, sua primeira visita ao Brasil só ocorreu no final de 1957, quando pôde fazer uma escala de quatro dias no Rio de Janeiro e se encontrar com Teixeira. No ano seguinte, finalmente concretizou o plano inicial, vindo para São Paulo. ${ }^{17}$

A chegada do francês ao Brasil não apenas deu início a uma relação político-acadêmica que durou décadas como também selou um movimento reflexivo que vinha sendo realizado tanto no Brasil quanto na França. Isso pode ser ilustrado com a fala de Friedmann na abertura do IV Congresso Mundial de Sociologia (1959), quando era presidente da ISA:

\footnotetext{
${ }^{14}$ Em outubro de 1959, no Rio de Janeiro, a CLAPCS organizou o Seminário Internacional "Resistência à mudança: fatores que impedem ou dificultam o desenvolvimento", que contou com comunicações de Jacques Lambert, Florestan Fernandes, entre outros (Cf. CLAPCS, 1960).

${ }^{15}$ Conf. Resolução 24 da Conferência sobre o ensino de ciências sociais na América Latina. Arquivos da UNESCO, Paris.

${ }^{16}$ Cf. Carta de Georges Friedmann a Fernando de Azevedo, de $23 / 10 / 1954$, o francês confirma ter recebido carta de Teixeira convidando-o para ministrar um curso na USP no ano seguinte: "je suis três touché de cette invitation et serais heureux, en principe, de faire um séjour au Brésil" (Azevedo, 1954).

17 Após a sua passagem por São Paulo, em 1958, Friedmann ainda se encontrou com Anísio Teixeira no Rio de Janeiro, para discutirem a colaboração franco-brasileira no domínio da sociologia do trabalho (Cf. Azevedo, 1958).
}

A sociologia, estreitamente vinculada às outras ciências sociais, afirma-se cada vez mais como uma necessidade de tomada de consciência da sociedade industrial por ela mesma [...]. Ou seja, face ao progresso técnico do qual as ciências da natureza são as infatigáveis promotoras, a sociologia, se fosse mais bem equipada e constantemente consultada, poderia, controlando a introdução e a adaptação das coletividades e dos indivíduos, ajudar a encontrar um equilíbrio que ainda não existe em nenhuma parte do mundo.

[...] constatamos que a ambição do conhecimento científico se confunde com a exigência (ou a nostalgia) da ação. A ação do sociólogo pode ser projetada por ele essencialmente como a transformação militante do meio. Mas ele pode também considerar que sua missão é, antes de tudo, ajudar o homem na sua adaptação a esse novo meio. [...] os sociólogos ocidentais contribuem para a transformação, e em todo caso, para a reforma do meio social por intermédio das pesquisas sobre a urbanização, as grandes organizações administrativas, a saúde mental, o sistema hospitalar, as relações raciais, etc. [...].

O papel do sociólogo é diferente segundo a coletividade demandante: uma grande administração pública (ou seja, o Estado), uma empresa industrial, comercial, financeira, uma corporação econômica, um sindicato, uma associação profissional. (Friedmann, 1960, p. 11, 15,16, grifo do autor, tradução nossa). ${ }^{18}$

Na França, como afirma Tanguy (2017), o renascimento da sociologia, no período pós-guerras, deu-se a partir do reencontro entre as políticas modernizadoras e os empreendimen-

18 "La sociologie, étroitement liée aux autres science sociales, s'affirme de plus en plus comme une nécessaire prise de conscience de la société industrielle par ellemême [...] Autrement dit, face au progrès technique dont les sciences de la nature sont les infatigables promoteurs, la sociologie, s'il était mieux équipé et plus souvent consulté, pourrait en contrôler l'introduction, y mieux adapter les collectivités et les individus, aider les sociétés industrielles à trouver un équilibre qu'elles n'ont encore, quelle que soit leur structure, nulle part atteint dans le monde.

[...] on constate que l'ambition de la connaissance scientifique se mêle à l'exigence (ou à la nostalgie) de l'action. L'action du sociologue peut être concue par lui essentiellement comme la transformation militante du milieu. Mais il peut aussi considérer que sa mission est avant tout d'aider l'homme dans son adaptation à ce nouvel environnement [...] les sociologues occidentaux contribuent à la transformation, et en tout cas à la réforme, du milieu social par des recherches sur l'urbanisation, les grandes organisations administratives, la santé mentale, le système hospitalier, les relations raciales, etc. [...]

Le rôle du sociologue est différent selon la collectivité qui fait appel à lui: une grande administration publique (c'est-à-dire l'Etat), une entreprise industrielle, commerciale, financière, une corporation économique, un syndicat, une association professionnelle." 
tos intelectuais mobilizados para esse fim. A consequência disso foi a hegemonização, ao longo dos anos 1950 e 1960, do método de investigação empírico e um modelo de ciência social muito mais próximo das ciências da natureza que das disciplinas da cultura.

Paradigmáticas, nesse sentido, foram as pesquisas realizadas no Institut des Sciences Sociales du Travail (ISST), em particular o projeto sobre as atitudes dos operários frente ao processo de transformação técnica na indústria, dirigido por Alain Touraine e Jean-Daniel Reynaud. Financiada pela Agência Europeia de Produtividade da OECE, a pesquisa se estendeu de 1954 a 1957, e seus resultados tiveram desdobramentos por mais uma década. O método era o da pesquisa empírica, com a aplicação de questionários por amostragem, com perguntas abertas e fechadas. Como aponta Tanguy (2017), o ISST assegurou aos jovens sociólogos uma instituição que pudesse financiar as ambiciosas pesquisas no mundo industrial e do trabalho. Sem poder alongar muito sobre essa experiência, que mereceria uma análise mais minuciosa, vale destacar que o modelo desenvolvido no ISST foi exportado para o Chile, quando, a pedido da Universidade do Chile e indicado por Friedmann, Touraine e Reynaud organizaram a primeira pesquisa de sociologia industrial naquele país (Di Tella et al., 1966). ${ }^{19}$ Anos mais tarde, Touraine buscou estabelecer com o CESIT uma grande pesquisa empírica e comparativa sobre as atitudes e a consciência operária na França, no Brasil e na Argentina. ${ }^{20}$

No caso específico da USP, o mundo industrial e do trabalho foi, progressivamente, ganhando relevância como objeto de pesquisa e tema de eventos acadêmicos ou disciplinas. Em 1955, por exemplo, no curso de "Dinâmica Social" ministrado por Azevedo para os alunos do terceiro ano de ciências sociais, apareceu,

\footnotetext{
${ }^{19}$ Essa pesquisa foi encomendada pelo Instituto de Sociologia da Universidade do Chile e teve como um de seus assistentes o jovem estudante Enzo Faletto, que se recorda de ter ingressado numa mina de carvão para entrevistar os operários, sob a supervisão de Alain Touraine (Rego, 2007).

${ }^{20}$ Essa pesquisa acabou não tendo a participação dos brasileiros, pois, com o Golpe de 64, o CESIT perdeu a sua força inicial, e Leôncio Martins Rodrigues, nome indicado para dirigir a pesquisa no Brasil, perdeu o interesse no projeto, preferindo ir trabalhar com FHC em Santiago do Chile.
}

pela primeira vez, na bibliografia obrigatória, um artigo de Friedmann. ${ }^{21}$ No ano seguinte, no curso de "Sociologia Aplicada", Cardoso ministrou seminários sobre "Os problemas sociais da sociedade de classe", que continha uma extensa bibliografia de sociologia industrial norte-americana (Cf. Programas..., [19--]). Paralelamente, foram registrados vários seminários e palestras dadas por Simão, Juarez Lopes e Cardoso para sindicatos patronais e operários, assim como para grandes empresas. Em 1960 e 1961, foram organizados dois cursos na USP sobre sociologia industrial, o primeiro com a presença de Touraine.

Portanto, a pesquisa que os dois jovens estudantes realizaram em 1959, no congresso dos metalúrgicos, situa-se no ínterim da mudança de influência da sociologia industrial norte-americana para a sociologia do trabalho francesa, assim como da passagem de uma sociologia sobre o mundo do trabalho, realizada isoladamente, para um projeto coletivo de pesquisas empíricas. Entendida como uma forma de se voltar para a realidade concreta e atual, os autores acreditavam que "a sociologia deve colocar como tarefa essencial a análise da crise de mudança por que passa a sociedade de classe" (Chucid; Löwy, 1962, p. 133) e, por conta disso, "decidimos selecionar um objeto de pesquisa que fornecesse, mesmo modestamente, subsídios à compreensão do processo de emergência do proletariado como classe social com papel histórico a desempenhar" (Chucid; Löwy, 1962, p. 133). Justificavam, portanto, que a escolha do tema carregava a convicção da necessidade de focalizar os setores cruciais da realidade social, de "forma a permitir o controle racional dos processos de transformação sociocultural que ela atravessava" Chucid; Löwy, 1962, p. 133).

Evidentemente, essas passagens expressam certa adesão, ainda que crítica, à visão de modernização pela qual estaria passando a sociedade brasileira. A crítica à contemplação do progresso técnico, que Löwy desenvolverá em seus trabalhos posteriores, não estava presente naquele momento. Ele buscava, principalmen-

${ }^{21}$ Tratava-se de "Technological change and human relations". 
te na forma como expôs seu objeto no Artigo de 70, encontrar um meio de superação ou uma alternativa à "modernização capitalista", apostando na ação revolucionária do proletariado.

\section{A PROBLEMATIZAÇÃO DO MÉTODO}

O questionário da pesquisa de 1959 foi elaborado com a ajuda de Albertino Rodrigues, então diretor do DIEESE, e recebeu comentários e opiniões de dirigentes operários e de pessoas vinculadas ao movimento sindical. As questões buscavam abordar 28 itens relativos a atributos pessoais dos indivíduos, à sua participação na vida sindical e às suas opiniões e atitudes. Os pesquisadores queriam testar as hipóteses levantadas previamente, tomando como referência a obra de Richard Centers sobre o radicalismo nos EUA (CENTERS, 1949). ${ }^{22}$ Após a elaboração, o questionário foi impresso em papel timbrado do DIEESE e distribuído entre os delegados sindicais, que responderam de forma anônima.

Após a coleta dos dados no Congresso, "iniciou-se o trabalho de elaboração e análise, no qual teve papel decisivo o Professor Azis Simão [...] orientando os autores em todos os passos decisivos" (Artigo 62, p. 135). Foi nessa fase que os métodos e as perspectivas analíticas entre o Artigo de 62 (Chucid e Löwy) e o Manuscrito/Artigo de 70 (Löwy) se diferenciaram. O primeiro buscava "apreender o processo de radicalização da vanguarda sindical brasileira em sua fase mais plenamente realizada, o que poderia indicar a tendência a ser seguida por todas as áreas do país, na medida em que se alastra e intensifica os processos de

${ }^{22}$ Esse livro sobre radicalismo foi uma das referências básicas nos Seminários ("Os problemas sociais na sociedade de classe") que FHC ministrou na disciplina de Sociologia Aplicada de Florestan, durante a segunda metade da década de 1950. Centers realizou um survey sobre atitudes da população branca, de 21 anos ou mais, numa amostra de 1100 indivíduos, obtida em julho de 1945. Em entrevista, publicada no dossiê "A obra polissêmica de Michael Löwy", o autor diz que a escolha desse livro se deu por acaso. industrialização e urbanização" (Artigo 62, p. 138). Dessa forma, os autores se restringiram a analisar os dados obtidos das respostas dos delegados do Rio de Janeiro e de São Paulo, excluindo as demais regiões, por considerarem que essas duas expressavam as opiniões da vanguarda sindical do proletariado brasileiro. Já no Manuscrito/Artigo de 70, Löwy optou por analisar as respostas do conjunto dos delegados presentes no congresso, selecionando os itens que melhor pudessem elucidar "problemas relativos à estrutura da consciência de classe do grupo" (Manuscrito, p. 1). O seu referencial teórico para essa questão foi o marxismo, em particular os apontamentos de Lenin em Que Fazer?

Os métodos utilizados para a análise dos dados coletados foram: tabulação horizontal; agrupamento de certos conjuntos de respostas em índices escalonados; comparação das respostas e dos índices; e elaboração das hipóteses sugeridas pelos dados. Na análise desenvolvida no Artigo de 62 (Chucid e Löwy), buscou-se constituir Índices de Status, cruzando-se salário, qualificação profissional e nível educacional para precisar certo lugar ocupado pelo trabalhador no seio do grupo operário. "O mecanismo da construção do índice é o seguinte: para cada um dos três itens que compõem o índice, estabelecem-se três valores, cada um dos quais recebe um peso, de 0 a 2" (Artigo 62, p. 146). Assim, os totais obtidos pela soma dos pesos de cada item foram distribuídos em três níveis, seguindo o esquema de Centers: índice de integração na vida urbana, índice de participação na vida sindical e, por fim, índice de radicalismo-conservadorismo.

No Manuscrito/Artigo de 70, Löwy optou por organizar as respostas dos delegados de uma forma mais simples, a partir de porcentagens. Nesse sentido, não buscou construir uma escala das atitudes dos operários, que iria do conservador ao radical, e sim cruzar a análise das respostas, os dados quantitativos, com a experiência do próprio pesquisador no meio operário. Buscava-se, talvez, distanciar-se de 
uma "sociologia descritiva", no sentido atribuído por Lucien Goldmann, e aproximar-se de um estudo mais analítico.

Os autores partiam da compreensão de que a classe operária e o seu movimento sindical haviam se tornado um sujeito político fundamental no "processo de transformação social” do Brasil. Por conta disso, estavam conscientes de que a sondagem e a metodologia da pesquisa colocavam limitações, permitindo apenas levantar hipóteses sobre o grupo, sem que elas fossem automaticamente generalizadas para toda a classe. No Artigo de 70, a preocupação de Löwy não era a de apresentar um panorama da consciência de classe, mas refletir sobre os mecanismos de estruturação dela a partir de um estudo de caso.

Ainda sobre a metodologia, vale a ressalva apontada no Manuscrito:

As condições em que foi possível a realização deste trabalho não permitiram a verificação da validez e fidedignidade do questionário, e o emprego de rigor estatístico no tratamento e colheita dos dados; tais fatores, e em geral, o próprio tipo de abordagem adotado, impedem a formulação de qualquer conclusão categórica. Trata-se de uma sondagem, um 'survey' de proporções reduzidas, num setor da realidade social quase inexplorado sociologicamente, e que não pretende senão levantar hipóteses que servirão aos estudos posteriores do problema (Manuscrito, p. 1, grifo nosso).

\section{APROXIMAÇÕES}

Ainda que o método de um "survey reduzido" produza várias limitações para as pesquisas que buscam lidar com as opiniões ou subjetividades dos agentes sociais investigados, no caso da pesquisa de 1959 de Löwy e Chucid, ela nos apresenta um interessante recorte sobre a classe trabalhadora brasileira. Como disseram os autores, "o material obtido reflete, em linhas gerais, as tendências imperantes no seio desses conclaves" (Artigo de 62, p. 135). Vejamos algumas questões que a pesquisa conseguiu captar.

Em todos os textos, é ressaltada uma tendência que vinha se desenvolvendo desde 1945, de maior autonomia dos sindicatos em relação ao Estado. Não se tratava de uma emancipação total ou de ruptura, mas "uma progressiva depuração nos sindicatos dos dirigentes mais abertamente ligados à classe patronal e ao governo" (Artigo 62, p. 141). As respostas obtidas dos delegados sindicais apontavam para uma tendência, no interior da vanguarda sindical metalúrgica, de crescimento da visão classista e, portanto, de ações com maior independência em relação aos patrões e ao Estado. As grandes greves de 1953 e 1957, ocorridas em São Paulo, eram demonstrativas de que os "pelegos" não tinham mais o total controle dos sindicatos.

No Artigo de 62 (Chucid e Löwy), essa tendência foi explicitamente comprovada pelo alto grau de radicalismo entre os delegados sindicais. O estudo concluiu que aqueles que expressavam opiniões e atitudes ideologicamente radicais tinham uma maior integração na vida urbana e uma maior participação na vida sindical. Esse grupo era composto, majoritariamente, por comunistas, socialistas e independentes, sendo os moderados e conservadores majoritariamente trabalhistas. No entanto, no Manuscrito, em sua reflexão sobre a estruturação da consciência de classe, Löwy pondera essa tese e afirma que "a industrialização e urbanização não são o único fator a influenciar este aspecto da consciência classista. O papel dos partidos políticos, a tradição local do movimento operário, a conjuntura sociopolítica, etc. são provavelmente elementos cruciais nesta área” (Manuscrito, p. 8).

No entanto, a pesquisa de 1959 também demonstra a existência de atitudes contraditórias no seio dessa vanguarda, quando tomamos como referencial o paradigma do antagonismo de classe. Mesmo entre o grupo dos comunistas, ideologicamente alinhados no campo "radical", havia um setor significativo, que considerava o conflito de classe como "mal-entendido": entre comunistas e socialistas, $22,2 \%$ não consideram o conflito entre patrões e empregados como interesses opostos. Esse dado "indica que devemos encarar com certa reserva a caracterização dos dirigentes simpatizantes do comunismo ou do socialismo como portadores de uma autêntica consciência revolucionária no sentido 
leninista” (Manuscrito, p. 8). Ou seja, embora críticos da burocracia estadonovista, esses dirigentes sindicais tendiam a assumir compromissos com a burguesia e o Estado, questão que se mostrará chave na década seguinte.

\section{CONCLUSÕES}

No Manuscrito e no Artigo de 70, Löwy buscou realizar uma análise marxista da estrutura da consciência de classe em um grupo de líderes sindicais. Utilizou como referencial teórico os clássicos que se preocuparam com essa questão, como o próprio Marx, Lenin, Lukács ${ }^{23}$ e, no texto publicado em francês, acrescentou um diálogo com Touraine. O esquema analítico do qual o autor parte é aquele apresentado por Lenin em Que Fazer?, que diferencia a consciência sindicalista (definida como "convicção de que é necessário reunir-se em sindicatos, lutar contra os patrões, exigir do governo a promulgação de tais ou quais leis de interesse dos operários, etc.) e a consciência socialdemocrata (ou seja, a consciência do antagonismo irreconciliável entre os interesses do proletariado e todo o regime político e social contemporâneo).

No entanto, Löwy aponta para uma particularidade da classe operária brasileira, pois sua adesão ao sindicato não significava uma imediata "consciência sindical", já que o sindicato era visto como um órgão de assistência social, uma extensão do Estado, questão que vinha sendo problematizada pelos estudos de Juarez Brandão Lopes (Cf. Lopes, 1964, 1967). Também aponta que a "consciência ideológica" (Manuscrito) ou a "consciência radical-ideológica” (Artigo de 70) era, no Brasil, precária, e isso teria implicações sobre a consciência sindical, impedindo-a de colocar em causa o regime econômico-social.

${ }^{23}$ Podemos dizer que o Manuscrito de Löwy foi o primeiro texto em que o autor exteriorizou sua primeira leitura de História e Consciência de Classe, realizada após contato com o livro de Lucien Goldmann. No entanto, essa leitura ainda não ressaltava diferenças entre Lukács e Lenin, nem outras reflexões importantes da obra do húngaro, como é o caso da reificação.
Do ponto de vista analítico, o Artigo de 70 (Löwy) é superior ao de 62 (Chucid e Löwy), não apenas porque o método marxista apresentou uma melhor abordagem do tema, mas, fundamentalmente, porque, diante das limitações que a pesquisa "survey reduzida" colocava aos autores, no Manuscrito/Artigo de 70, o autor pôde se desprender das questões formais de uma "sociologia científica" construída nos moldes uspianos da época e alçar voos a uma explicação mais totalizante, arriscando-se a apontar tendências. Nesse caso, contou não apenas com os dados positivos, como também com as experiências de um autor participante. E, por participante, não queremos ressaltar o método de observação que Löwy e Chucid realizaram no congresso metalúrgico de 1959, mas sua experiência de militância política, algo avesso aos olhos dos acadêmicos da USP, inclusive daqueles que estavam concentrados na leitura de $O$ Capital e dos marxistas. ${ }^{24}$ Essa militância o levou, desde muito cedo, a conhecer o movimento operário e suas lideranças sindicais e políticas, reformistas e revolucionárias, o que lhe deu uma sensibilidade que só se adquire por meio dessa vivência.

A depuração das respostas dos questionários por meio da construção de índices buscava apresentar uma cientificidade na análise de seu objeto e, a partir disso, projetar possíveis padrões de ação dos sujeitos. Esse método correspondia ao desejo e ao projeto de uma geração que buscava afirmar a sociologia como uma ciência e uma profissão, distanciando-se de qualquer forma de produção ensaística, "literária" ou "ideológica". Além disso, a forma como o Artigo de 62 (Chucid e Löwy) é exposto evidencia certa tentativa de neutralidade axiológica, algo que não existe no Manuscrito e no Artigo de 70 (Löwy).

O problema central do método utilizado no Artigo de 62 é que ele não consegue encontrar as conexões dos diversos complexos que existem

${ }^{24}$ A leitura predominante realizada no famoso Seminário d'O Capital separava um marxismo militante de um marxismo acadêmico. O próprio Fernando Henrique Cardoso, na Introdução de sua tese de doutorado, defendeu a separação entre um Marx político e um Marx científico. (Cf. Cardoso, 1962; Querido, 2011, 2016; Rodrigues, 2011). 
na totalidade social. Preso a um esquema positivo de cientificidade, a interconexão era adquirida a partir das próprias respostas dadas, faltando as interconexões históricas e as determinações exógenas ao grupo social, que só poderiam ser encontradas pelo método da abstração.

Porque, portanto, o Manuscrito, uma versão alternativa ao Artigo de 62, só veio a público em francês, no ano de 1970? Uma explicação é que o meio acadêmico brasileiro ainda não estava preparado para aceitar um texto que afirmasse o método marxista, menos ainda que se propusesse a aplicar o "esquema leninista” de consciência operária para a realidade brasileira. Isso seria considerado não científico e um trabalho ideológico. Ainda que uma parte da intelectualidade da USP se reunisse, desde 1958, para estudar as obras marxistas, isso ainda não se refletia em um aceite do marxismo como método científico e político, dois aspectos indissociáveis.

Nesse sentido, o Manuscrito de Löwy antecipou uma perspectiva de sociologia do trabalho que só se desenvolveria no final dos anos 1970, principalmente nos estudos sobre as greves operárias que varreram o país a partir de 1978. O interessante, nesse fato, é que essa nova geração não se aproximou do método de Löwy lendo o Artigo de 70, quase nunca citado, mas sim pela leitura de Lukács, em particular o livro História e Consciência de Classe, e a produção de outros marxistas.

Todos os textos aqui analisados apresentam uma tensão interna que se expressou na sociologia do trabalho brasileira dos anos 1950 e 1960, a qual, evidentemente, era a tensão existente no seio da própria classe trabalhadora, em particular em seus setores sindicalizados. Esse conflito ocorria, pois, na classe trabalhadora da época. Havia, por um lado, uma tendência ao conservadorismo na atuação, nas atitudes e nas expectativas sobre o seu futuro. Todavia, por outro, havia uma contestação da realidade socioeconômica do país. Faltaram estudos mais amplos e sistemáticos que pudessem comprovar, de fato, o peso real de uma ou de outra tendência. As importantes - mas metodologicamente limitadas - pesquisas sobre o mundo do trabalho e da indústria, realizadas pelos autores da USP dos anos 1960, acabaram por ressaltar a visão de que a classe operária brasileira seria conservadora. Elas acabaram servindo, durante décadas, como base de legitimação "científica" dos argumentos "ideológicos" contra a autonomia e a capacidade de ação e organização da classe operária brasileira.

O Manuscrito de Löwy, que deve ser lido relevando as limitações teóricas de um jovem pesquisador, buscava apresentar uma visão dialética do problema e, por conta disso, foi capaz de apontar tendências que acabaram se confirmando nos anos posteriores, principalmente no que diz respeito ao potencial contestador que o autor já visualizava, em 1959, entre os trabalhadores brasileiros. O Golpe de 64 acabou por absolutizar essas tendências conservadoras, impedindo que muitos vissem, no imediato pós-golpe, o fervilhar de uma nova geração que acabaria por se expressar no final dos anos 1970.

Como já apontamos anteriormente, os autores pretendiam continuar essa pesquisa aplicando o mesmo questionário na base operária, o que possibilitaria uma análise comparativa entre as opiniões e atitudes das lideranças e do operário de base. Os motivos do abandono desse propósito não estão explícitos. Talvez a precariedade financeira e instrumental em que se encontrava a pesquisa nas ciências sociais naquele período explique a desistência de um projeto que demandaria um esforço enorme para seu desenvolvimento. Basta lembrar que os surveys de opinióes e atitudes dos operários realizadas na França, nos anos 1950, tinham como amostragem centenas e até milhares de operários, o que exigia financiamento, assistentes técnicos, pesquisadores, estatísticos e laboratórios de pesquisa. O CESIT foi uma tentativa de construir no Brasil, nos moldes do que existia na Europa, um moderno centro de reflexões sociológicas pautadas em pesquisas empíricas, mas esse projeto foi abortado prematuramente com o Golpe de 64. 


\section{REFERÊNCIAS}

ANTUNES, R. Classe operária, sindicatos e partido no Brasil: um estudo sobre a consciência de classe: da Revolução de 30 até a Aliança Nacional Libertadora. São Paulo: Editora Autores Associados: Cortez Editora, 1982.

- A rebeldia do trabalho: o confronto operário no ABC paulista: as greves de 1978/80. Campinas: São Paulo: Editora da UNICAMP: Editora Ensaio, 1988.

BRAGA, R. A política do precariado: do populismo à hegemonia lulista. São Paulo: Boitempo, 2012.

BROCHIER, C. La naissance de la sociologie au Brésil. Rennes: Presses Universitaires de Rennes, 2016.

CÂNDIDO, J. C. Entre a "política"e a "polícia": a constituicão e a crítica da sociedade industrial democrática na sociologia paulista dos anos 1950 e 1960. Dissertacão (Mestrado) - Universidade de São Paulo, São Paulo, 2002.

CARDOSO, F. H. Capitalismo e escravidão no Brasil meridional: o negro na sociedade escravocrata do Rio Grande do Sul. São Paulo: Difusão europeia do livro, 1962.

CENTERS, R. The Psychology of social classes: a study of class consciousness. Princeton: Princeton University press, 1949 .

CENTRO LATINO AMERICANO DE PESQUISA EM CIÊNCIAS SOCIAIS (CLAPCS). SEMINÁRIO INTERNACIONAL SOBRE "RESISTENNCIAS À MUDANCA: FATORES QUE IMPEDEM OU DIFICULTAM O DESENVOLVIMENTO", 1959. Anais... Rio de Janeiro: CLAPCS, 1960

CHAPOULIE, J.-M. La tradition sociologique de Chicago : 1892-1961. Paris: Seuil, 2001.

CHUCID, S.; LÖWY, M. Opiniões e atitudes dos líderes sindicais metalúrgicos. Revista Brasileira de Estudos Políticos, n. 13, 1962.

CUNHA, M. W. V. da. Burocratização das empresas industriais estudo monográfico. 1951. Tese (Doutorado) - Faculdade de Ciências Econômicas e Administrativas, Universidade de São Paulo, São Paulo, 1951.

DI TELLA, T. S. et al. Huachipato et Lota: étude sur la conscience ouvrière dans deux entreprises chiliennes. Paris: Éditions du Centre national de la recherche scientifique, 1966.

FERNANDES, F. Os problemas do método da investigação sociológica. Sociologia, v. 9, n. 4, 1947.

. Ensaios de sociologia geral e aplicada. São Paulo: Pioneira, 1960.

A sociologia numa era de revolução social. 2. ed. São Paulo: Zahar, 1962.

FESTI, R. A primeira geracão de sociólogos do trabalho no Brasil (1950/60) e seus diálogo com a "escola" francesa. In: CONGRESSO BRASILEIRO DE SOCIOLOGIA, 18., 2017, Brasília. Anais... Brasília: [S.n.], 2017. Disponível em: <http://www.sbs2017.com.br/anais/index.htm>. Acesso em: 1 dez. 2017.

FRIEDMANN, G. Technological change and human relations. The British Journal of Sociology, v. 3, n. 2, june 1952

Société et connaissance sociologique. Annales: economies, sociétés, civilisations, v. Extrait, n. 1, p. 9-17, fev. 1960.

GUIMARÃES, N. A.; LEITE, M. de P. A sociologia do trabalho industrial no Brasil: Desafios e interpretações. BIB. Revista Brasileira de Informação Bibliográfica em Ciências Sociais, v. 37, p. 39-59, 1994.

LOPES, J. R. B. Sociedade industrial no Brasil. São Paulo: DIFEL, 1964.
Crise do Brasil arcaico. São Paulo: Difusão Europeia do Livro, 1967.

LOPES, J. S. L.; PESSANHA, E.; RAMALHO, J. R. Esboço de uma história social da primeira geração de sociólogos do trabalho e dos trabalhadores no Brasil. Educação \& Sociedade, v. 33, n. 118, p. 115-129, mar. 2012.

LÖWY, M. Struture de la conscience de classe ouvrière au Brésil. Cahier internationaux de sociologie, n. 49, p. 133142, jul. 1970.

MICELI, S. et al. (Ed.). História das ciências sociais no Brasil. São Paulo: IDESP: Vértice, 1989.

QUERIDO, F. M. Crítica e autocrítica da modernidade: crise civilizatória e utopia anticapitalista em Michael Löwy. 2011. 212 f. Dissertação (Mestrado) - Universidade Estadual Paulista, Araraquara, 2011.

. Resistência Intelectual e engajamento político em Michael Löwy e Daniel Bensaïd: afinidades benjaminianas. Tese (Doutorado) - Universidade Estadual de Campinas, Campinas, 2016.

REGO, J. M. Entrevista com Enzo Faletto. Tempo social, v. 19, n. 1, jun. 2007.

RODRIGUES, L. S. A produção social do marxismo universitário em São Paulo: mestres, discípulos e "um seminário" (1958-1978). Tese (Doutorado) - Universidade de São Paulo, São Paulo, 2011.

RODRIGUES NETTO, L. M. Leôncio Martins Rodrigues Netto (depoimento, 2008). Rio de Janeiro: CPDOC/FGV: LAU/IFCS/UFRJ, 2010.

ROMÃO, W. DE M. Sociologia e política acadêmica nos anos 1960: a experiência do CESIT. São Paulo: Humanitas, 2006

SIMÃO, A. O voto operário em São Paulo. In: CONGRESSO BRASILEIRO DE SOCIOLOGIA, 1., 1955, São Paulo. Anais...São Paulo: [S.n.], 1955.

TANGUY, L. A sociologia do trabalho na França: pesquisa sobre o trabalho dos sociólogos (1950-1990). Traducão de Estela dos S. Abreu. São Paulo: Editora da USP, 2017.

VIÁ, S. C. da. Memorial para professora livre docente e adjunto. São Paulo: ECA-USP, 1986. Disponível em: $<$ http://www2.eca.usp.br/eca50anos/pt-br/content/sarahchucid-da-1986>. Acesso em: 1 dez. 2017.

\section{ARQUIVOS}

Arquivo da Administração da FFLCH-SP.

Arquivo Fernando de Azevedo, Arquivo IEB-USP. Arquivos da UNESCO, Paris.

Centro de Apoio à Pesquisa em História - Sérgio Buarque de Holanda (CAPH), do Departamento de História da FFLCH-USP

\section{ENTREVISTAS}




\section{MICHAEL LÖWY AND THE SOCIOLOGY OF WORK: the discovery of the class consciousness of the working class}

\section{Ricardo Festi}

The article analyzes and problematizes the rapid passage of the young Michael Löwy by the sociology of the work, when in 1959 realized research on the attitudes and the workers' conscience among metallurgical union leaders. We contextualize this study in the course of the process of institutionalization of Brazilian sociology, in particular the development of research on industry and work, carried out at the University of São Paulo in the 1950s and 1960s. We affirm that the author presented, in a manuscript unknown, a possible alternative to the style of sociology in force at USP. The reflections and conclusions of this article are anchored in consultations carried out in archives and in an interview with the author.

KEYwORDS: Michael Löwy. Sociology of work. Worker consciousness. Social thought. Intellectual history.

\section{MICHAEL LÖWY ET LA SOCIOLOGIE DU TRAVAIL: la découverte de la conscience de classe de la classe ouvrière}

\author{
Ricardo Festi
}

Larticle analyse et problématise le passage du jeune Michael Löwy par la sociologie du travail, lorsqu'en 1959 il réalise une recherche sur les attitudes et la conscience ouvrière parmi les dirigeants syndicaux métallurgiques. Nous contextualisons cette étude au cours du processus d'institutionnalisation de la sociologie brésilienne, en particulier le développement de la recherche sur l'industrie et le travail, menée à l'Université de São Paulo dans les années 1950 et 1960 . Nous affirmons que l'auteur a présenté, dans un manuscrit inconnu, une alternative possible au style de sociologie en vigueur à l'USP. Les réflexions et les conclusions de cet article sont ancrées dans des consultations menées dans les archives et dans une interview avec l'auteur.

Mots-CLÉs: Michael Löwy. Sociologie du travail. Conscience ouvrière. Pensée sociale. Histoire intellectuelle. 